\title{
XLIII. On the specific heat of saturated vapours
}

\section{John P. Dalton M.A.}

To cite this article: John P. Dalton M.A. (1907) XLIII. On the specific heat of saturated vapours, Philosophical Magazine Series 6, 13:76, 536-542, DOI: 10.1080/14786440709463628

To link to this article: http://dx.doi.org/10.1080/14786440709463628

册 Published online: 16 Apr 2009.

Submit your article to this journal 준

Џ Article views: 4

Q View related articles $₫$ 
XLIII. On the Specific Heat of Saturated Vapours. By John P. Dalton, M.A., Carnegie Research Scholar *

A. According to van der Waals's Equation.

A WELL-KNOWN thermodynamic relation is expressed by the equation

$$
h_{s}=\mathrm{C}_{v}+\mathrm{T}\left(\frac{\partial p}{\partial \mathrm{T}}\right) \frac{d v}{d},
$$

where $h_{s}$ is the specific heat of the saturated vapour, and $\frac{d v}{d \mathrm{~T}}$ is calculated along the saturation line.

Hence

$$
h_{s}=\mathrm{C}_{v}+\frac{\mathrm{RT}}{v-b} \frac{d v}{d \mathrm{~T}},
$$

or, in "reduced" magnitudes,

$$
h_{s}=\mathrm{C}_{v}+\frac{3 \mathrm{R} \theta}{3 \omega-1} \frac{d \omega}{d \theta} .
$$

At "inversion" points, $i . e$. at points where the specific heat of the saturated vapour changes its sign, $h_{s}=0$. The curve of inversion points is, therefore, determined by the equation

$$
-\frac{\mathrm{C}_{v}}{\mathrm{R}}=\frac{3}{3 \omega-1} \theta \frac{d \omega}{d \theta} .
$$

Now, the law of corresponding states does not involve the correspondence of thermal quantities. But, considering that $\mathrm{C}_{v}$ does not vary with the volume, and probably comparatively little with the temperature, $\mathrm{C}_{v}$ may be assumed constant and equal to $\mathrm{C}_{v=\infty}$. At infinite volume the gas laws are obeyed, hence

$$
\mathrm{R}=\mathrm{C}_{v=\infty}\left(\gamma_{\infty}-1\right),
$$

where $\gamma_{\infty}=\mathrm{C}_{p} / \mathrm{C}_{v}$ at large volume.

The equation to the curve of inversion points may now be written in terms of $\gamma$,

$$
\gamma_{\infty}=1-\frac{3 \omega-1}{3} \frac{1}{\theta} \frac{d \theta}{d \omega} .
$$

Using the saturation constants given in a previous paper, $\frac{d \theta}{d \omega}$ was calculated by means of Stirling's interpolation formula, and the right member of the above equation evaluated.

* Communicated by Prof. J. P. Kuenen, Ph.D. 
Specific Heat of Saturated Vapours.

\begin{tabular}{|c|c|c|c|}
\hline$\theta$ & $\gamma_{\infty}$. & $\theta$. & $\gamma \infty$. \\
\hline $\begin{array}{l}0.25 \\
.30 \\
.35 \\
.40 \\
.45 \\
.50 \\
.55 \\
.60\end{array}$ & $\begin{array}{l}1 \cdot 0804 \\
1 \cdot 0983 \\
1 \cdot 1164 \\
1 \cdot 1341 \\
1 \cdot 1509 \\
1 \cdot 1660 \\
1 \cdot 1790 \\
1 \cdot 1896\end{array}$ & $\begin{array}{r}0.65 \\
.70 \\
.75 \\
.80 \\
.85 \\
.90 \\
.95 \\
1.00\end{array}$ & $\begin{array}{l}1 \cdot 197 \cdot 2 \\
1 \cdot 2013 \\
1 \cdot 2011 \\
1 \cdot 1955 \\
1 \cdot 1838 \\
1 \cdot 1637 \\
1 \cdot 1267 \\
1 \cdot 0000\end{array}$ \\
\hline
\end{tabular}

and on plotting these values the curve shown in fig. 1 was obtained.

Fig. 1.

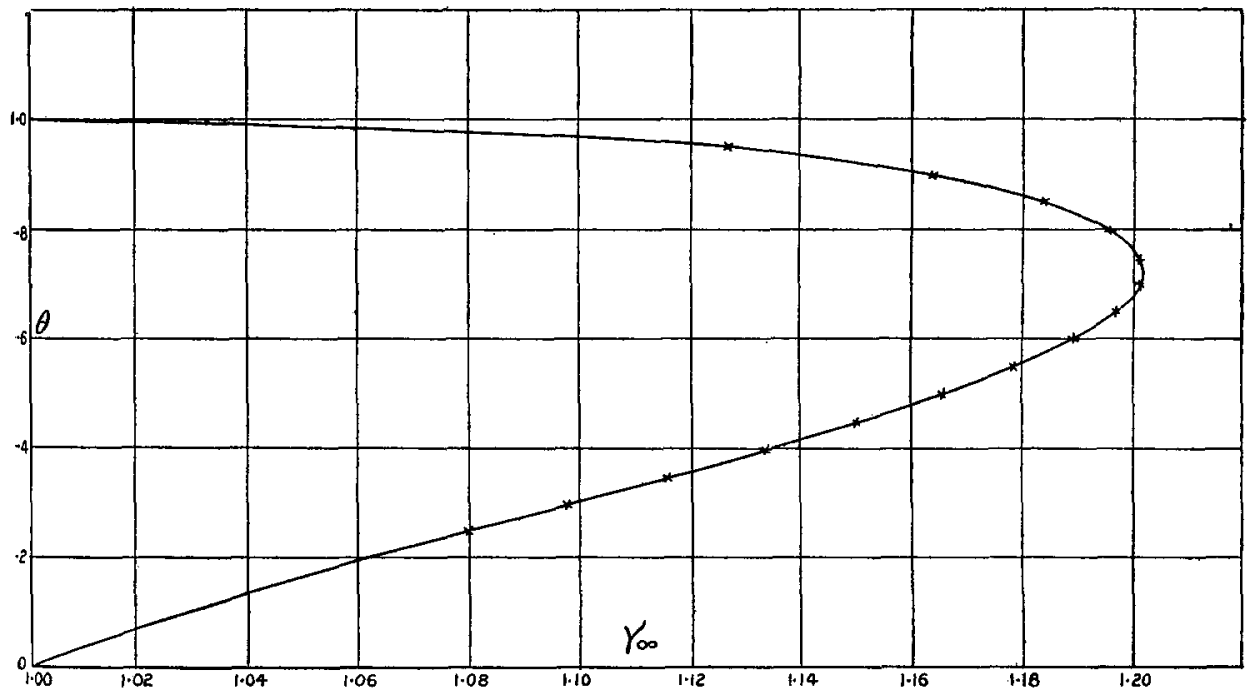

From this it appears that the specific heat of saturated vapours whose $\gamma_{\infty}>1.202$ must be of invariable sign, viz. negative. No "inversion" can occur in monatomic vapours such as $\mathrm{Hg}, \mathrm{A}, \mathrm{He}$ whose $\gamma_{\infty}=1 \cdot 67$, or in such diatomic gases as $\mathrm{H}_{2}, \mathrm{O}_{2}, \mathrm{~N}_{2}$ whose $\gamma_{\infty}=1 \cdot 41$, and the specific heat of their saturated vapours must always be negative. For vapours such as ether, chloroform, benzene, \&c. whose $\gamma_{\infty}<1.202$ there must be two inversion temperatures which become further apart as $\gamma_{\infty}$ gets smaller. 
From fig. 1 the following table of inversion points was derived :-

\begin{tabular}{|c|c|c|}
\hline \multirow{2}{*}{$\gamma_{\infty}}$. & \multicolumn{2}{|c|}{ Inversion Temperatures. } \\
\hline & $\theta_{1}$. & $\theta_{2}$. \\
\hline 1.00 & $0 \cdot 000$ & $1 \cdot 00$ \\
\hline 1.02 & 0.07 & 0.995 \\
\hline 1.04 & $0 \cdot 14$ & 0.99 \\
\hline 1.06 & $0 \cdot 195$ & $0-985$ \\
\hline $1 \cdot 08$ & 0.25 & 0.98 \\
\hline $1 \cdot 10$ & 0.305 & 0.970 \\
\hline $1 \cdot 12$ & $0 \cdot 36$ & 0.96 \\
\hline $1 \cdot 14$ & 0.42 & 0.935 \\
\hline $1 \cdot 16$ & 0.48 & 0.905 \\
\hline $1 \cdot 18$ & 0555 & 0.86 \\
\hline $1 \cdot 20$ & $0 \cdot 68$ & 0765 \\
\hline $1 \cdot 202$ & 0.725 & 0.725 \\
\hline
\end{tabular}

Besides the fact that there must be two inversion points or none at all (except in the limiting case when the two coincide), it is also worth noting that the region to the right of the curve is the region of negative specific heats, to the left, $i . e$. enclosed by the curve, of positive; while on the curve itself the specific heat is zero. Hence

(1) Saturated vapours of substances whose $\gamma_{\infty}>1.202$ have always a negative specific heat;

(2) Saturated vapours of substances whose $\gamma_{\infty}<1.202$ have a specific heat that, as the temperature rises, is first negative, then positive, and finally negative again ;

(3) In the limiting case when $\gamma_{\infty}=1.202$ the two inversion points coincide; the specific heat is then always negative. ex'ept at one point when it becomes zero.

Kamerlingh Onnes*, in a paper dealing with the reduced $\psi$-surface, makes use of the equation (which is not quite exact)

$$
\frac{\theta}{\omega} \frac{d \omega}{d \theta}=-\frac{1}{\gamma-1},
$$

for the determination of inversion temperatures according to van der Waals's equation, and finds that according to it the limit of $\gamma_{\infty}$ is 1.195 if inversion is to be possible. He does not seem to note, however, that every saturated vapour that changes its sign once, must do so a second time, and his division of substances into classes does not appear to be entirely in accordance with the above results.

\footnotetext{
* Kamerlingh Onnes, Comm. Leid. No. 66 (1900).
} 


\section{B. Experimental Evidence.}

As in the case of ordinary specific heats one might expect the foregoing results to hold qualitatively for real substances; but, although observations of inversion points are neither sufficiently numerous nor accurate to afford a satisfactory test, an attempt was made to obtain a curve more closely adapted to experimental results.

For the saturation constants the known properties of a normal substance may be used instead of the equation of state. Isopentane was taken as a typically normal substance. Its properties have been fully investigated by S. Young*, whose data have here been user.

The equation to the curve of inversion points is

$$
-\mathrm{C}_{v}=\mathrm{T}\left(\frac{\partial p}{\partial \mathrm{T}}\right)_{v} \frac{d v}{d \mathrm{~T}} \text {. }
$$

The assumption was made that for all values of $\theta, \frac{\mathrm{C}_{v}}{\mathrm{C}_{v=\infty}}$ along the saturation line is the same function of $\theta$, so that

$$
\text { or } \quad \begin{aligned}
\mathrm{C}_{v} & =\mathrm{C}_{v=\infty} \phi(\theta), \\
\mathrm{C}_{v} & =\frac{\mathrm{R}}{\gamma_{\infty}-1} \phi(\theta) .
\end{aligned}
$$

The above equation may therefore be rewritten in terms of $\gamma$,

$$
\gamma_{\infty}=1-\frac{\mathrm{R}}{\mathrm{T}\left(\frac{\partial p}{\partial \mathrm{T}}\right) \frac{d v}{d \mathrm{~T}}} \phi(\theta) .
$$

C. Dieterici†, as a result of calorimetric experiment, has determined $\mathrm{C}_{v}$ for isopentane along the saturation line, and has also calculated $\mathrm{T}\left(\frac{\partial p}{\partial \mathrm{T}}\right)_{v} \frac{d v}{d \mathrm{~T}}$; in the following, the values given by him have been used. $\phi(\theta)$ may therefore be evaluated for various values of $\theta$, if $\mathrm{C}_{v=\infty}$ is known. For this purpose, $\mathrm{C}_{p}-\mathrm{C}_{v}$ was calculated from Young's data $\ddagger$ at a temperature of $30^{\circ} \mathrm{C}$., and as near the saturation volume as possible. This gave a value $\mathrm{C}_{p}-\mathrm{C}_{v}=0 \cdot 028 . \quad \mathrm{C}_{v}$ at that temperature is given by Dieterici $=0.361$; hence, $\gamma$ at that point $=1 \cdot 08$. This was assumed to be equal to $\gamma_{\infty}$. From the gas laws it follows that $\left(\mathrm{C}_{p}-\mathrm{C}_{v}\right)_{\infty}=0.0276$ for isopentane; and since $\gamma_{\infty}=1.08, \mathrm{C}_{v=\infty}$ must be $0 \cdot 345$. By using the

* S. Young, Proc. Phys. Soc. xiii. pp. 602-657 (1894).

† C. Dieterici, Ann. d. Physik, xii. pp. 602-657 (1903).

$\ddagger$ Loc. cit. 
above equation, and determining $\phi(\theta)$ by this method the following results (plotted in fig. 2) were obtained :-

\begin{tabular}{|c|c||c|c|}
\hline$\theta$. & $\gamma_{\infty}$ & $e$. & $\gamma_{\infty}$. \\
\hline 0.5924 & 1.0735 & 0.9180 & $1 \cdot 1310$ \\
0.6359 & 1.0816 & 0.9397 & $1 \cdot 1201$ \\
0.6793 & $1 \cdot 0966$ & 0.9614 & $1 \cdot 1089$ \\
0.7227 & $1 \cdot 1121$ & 0.9722 & 1.0879 \\
0.7661 & 1.1314 & 0.9831 & 1.0708 \\
0.8094 & 1.1350 & 0.9896 & 1.0533 \\
0.8529 & 1.1387 & 0.9961 & 1.0363 \\
0.8746 & 1.1377 & 0.9983 & 1.0219 \\
0.8963 & 1.1368 & & \\
\hline
\end{tabular}

Fig. 2.

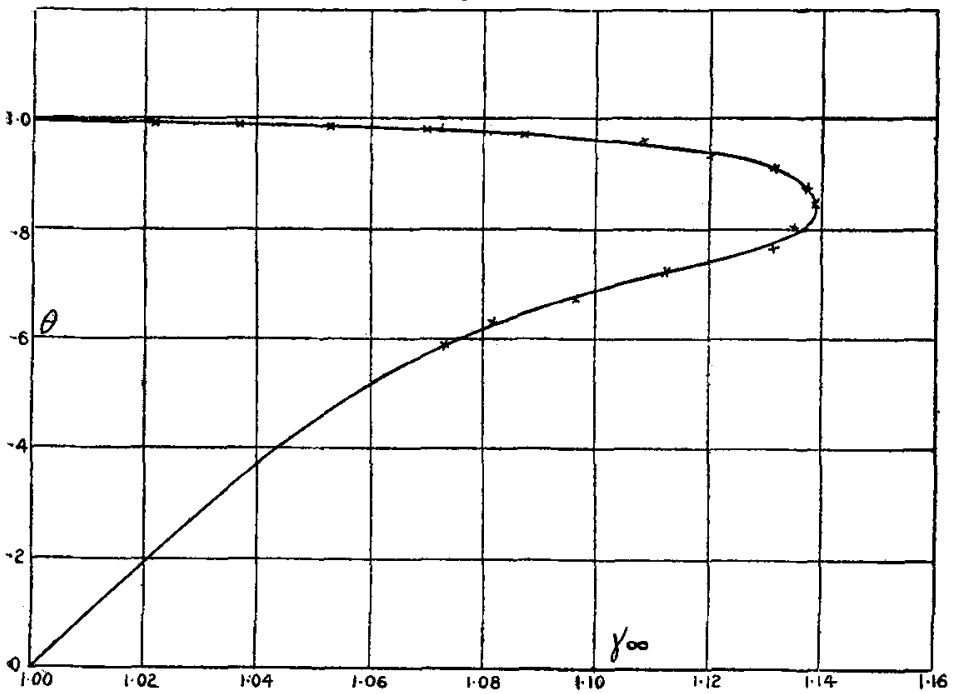

The general features of the diagram show fair agreement with that deduced from the equation of state. In this case, however, a still lower value of $\gamma_{\infty}$ is necessary to render possible an inversion point. From the diagram the following "Table of Inversion Temperatures for Normal Substances" has been derived:-

\begin{tabular}{|l|l|l|}
\hline & & \\
\hline$\gamma_{\infty}$ & $\theta_{1}$ & $\theta_{2}$. \\
\hline 1.02 & 0.19 & 0.995 \\
1.04 & 0.375 & 0.99 \\
1.06 & 0.515 & 0.985 \\
1.08 & 0.62 & 0.98 \\
1.10 & 0.69 & 0.96 \\
1.12 & 0.74 & 0.94 \\
1.139 & 0.835 & 0.835 \\
\hline
\end{tabular}


For normal saturated vapours, therefore, we might expect

(1) a negative specific heat for $\gamma_{\infty}>1 \cdot 139$;

(2) a specific heat first negative, then positive, and finally negative for $\gamma_{\infty}<1 \cdot 139$; and

(3) a negative specific heat vanishing at $\theta=0.835$ for $\gamma_{\infty}=1 \cdot 139$.

J. D. van der Waals* divides vapours into two classes: (1) when $\gamma<1 \cdot 07$ the sign of the specific beat is positive, and (2) when $\gamma>1.08$ it is negative. When $\gamma$ does not differ much from $1 \cdot 08$, nothing definite can be asserted about the sign of the specific heat.

Observations of actual inversion points are hardly sufficiently numerous to enable a direct comparison to be made between the foregoing results and experimental data. The few, however, that are known are here given.

\begin{tabular}{|c|c|c|c|}
\hline Acetone.......... & $\begin{array}{c}\gamma_{\infty} . \\
1 \cdot 132 \text { (Wiedemann) }\end{array}$ & $\begin{array}{c}\theta \text { observed. } \\
0.92 \text { (Cazin) }\end{array}$ & $\begin{array}{c}\theta_{1} \text { or } \theta_{2} \text { from Table. } \\
0.91\end{array}$ \\
\hline Benzene.......... & $1 \cdot 129($ do. & $\left\{\begin{array}{l}0.67 \text { ( do. ). } \\
0.70 \text { (Dupré). }\end{array}\right\}$ & 0.77 \\
\hline Chloroform & $\begin{array}{l}1 \cdot 139 \text { ( do. } \\
1 \cdot 110 \text { (Müller) }\end{array}$ & 0.74 (do. do.). & $\begin{array}{l}0.825 \\
0.72\end{array}$ \\
\hline
\end{tabular}

The degree of correspondence is sufficient to make one regret that further comparison is at present impossible; it justifies, however, a rejection of L. Natanson's $†$ "first approximation" that inversion occurs in various vapours at corresponding temperatures, and of his subsequent deduction of an inversion point for hydrogen.

\section{Abnormal Substances.}

An attempt was made to extend the foregoing method to abuormal substances, of which methyl alcohol was taken as an example. Data for the calculation of $\mathrm{T}\left(\frac{\partial p}{\partial \mathrm{T}}\right)_{v} \frac{d v}{d \mathrm{~T}}$ were obtained from the researches of Ramsay and Young $\ddagger$. In this case, however, no data are available for the determination of $\phi(\theta) . \quad C_{v}$ was therefore considered constant, and equal to $\mathrm{C}_{v=\infty}$. The resulting $\left(\gamma_{\infty}, \theta\right)$ curve was similar to that shown in fig. 2 , but the maximum value of $\gamma_{\infty}$ on the curve was much lower than that for normal substances. It would seem,

* van der Waals, Beibl. Bd. ii. p. 331 (1878).

† L. Natanson, Zeits. f. phys. Chem. xvii. p. 276 (1895).

$\mp$ Ramsay and Young, Phil. Trans. clexviii. A. pp. 57-93 (1887) and Phil. Mag. [5] xxiv. pp. 196-212 (1887). 
then, that abnormality diminishes the possibility of the existence of an inversion point by lowering the value of $\gamma_{\infty}$ above which inversion is impossible. How far this conclusion is affected by the assumption $\phi(\theta)=$ constant $=1$ it is at present impossible to say; and in the elucidation of this point there is still plenty of scope for further research.

University College, Dundee, February 1907.

XLIV. On the Relation of the Field at the Point of an Electrified Needle to the Mechanical Force resulting. By F. B. Young, B.A.*

THE present research was carried out in the Physical Laboratory of University College, Bristol, under the direckion of Professor Chattock, in order to obtain a correction factor for certain values found by him for the field which was just sufficient to produce discharge at the extremity of a needle $\dagger$. These values were obtained by measuring the pull of an electrified plate on an earth-connected needle opposite and normal to the plate and protruding through an earth-connected surface. The needle being cylindrical and ground to a hemispherical point this pull $(\mathrm{P})$ is a function of the field $(f)$ at the centre of the point.

Fig. 1 is a section of the point, $R$ being its radius, $S$ the electrical density at the centre of the point, and $\sigma \mathrm{S}$ the density at any other part of its surface. The pull on the surface of the annulus shown, resolved parallel to the axis of the point, is

whence

$$
4 \pi^{2}(\sigma \mathrm{S})^{2} \mathrm{R}^{2} \sin \theta \cos \theta d \theta ;
$$

$$
\begin{aligned}
& \mathrm{P}=2 \pi^{2} \mathrm{R}^{2} \mathrm{~S}^{2} \int_{0}^{\frac{\pi}{2}} \sigma^{2} \sin 2 \theta \cdot d \theta \\
& =\frac{\mathrm{R}^{2} f^{2}}{8} \int_{0}^{\frac{\pi}{2}} \sigma^{2} \sin 2 \theta d \theta \text {; } \\
& f=a \frac{\sqrt{8 \mathrm{P}}}{\overline{\mathrm{R}}}, \quad . \quad . \quad . \quad . \quad . \quad . \quad . \quad . .
\end{aligned}
$$

where

$$
a=\frac{1}{\sqrt{\int_{0}^{\frac{\pi}{2}} \sigma^{2} \sin 2 \theta d \theta}} .
$$

* Communicated by Prof. A. P. Chattock.

† Phil. Mag. Sept. 1891. 